This document is confidential and is proprietary to the American Chemical Society and its authors. Do not copy or disclose without written permission. If you have received this item in error, notify the sender and delete all copies.

\title{
Directed Insertion of Light-Activated Proteorhodopsin Into Asymmetric Polymersomes from an ABC Block-Copolymer
}

\begin{tabular}{|r|l|}
\hline Journal: & Nano Letters \\
\hline Manuscript ID & nl-2019-001616.R2 \\
\hline Manuscript Type: & Communication \\
\hline Complete List of Authors: & $\begin{array}{l}\text { Gaitzsch, Jens; Universitat Basel, Chemistry } \\
\text { Hirschi, Stephan; Universitat Bern, } \\
\text { Freimann, Sven; Universitat Basel, Chemistry } \\
\text { Fotiadis, Dimitrios; Universität Bern } \\
\text { Meier, Wolfgang; Universitat Basel, Department of Chemistry }\end{array}$ \\
\hline
\end{tabular}

\section{SCHOLARONE ${ }^{\text {M }}$ \\ Manuscripts}


Keywords: Self-Assembly, Vesicles, Triblock-Copolymers, Asymmetric Membranes, Proteopolymersomes, Proteorhodopsin

Amphiphilic block-copolymers and their self-assemblies have proven to be useful assets in synthetic biology, particularly as nanoreactors or as drug-delivery systems.1-2 $\mathrm{A}$ wide range of amphiphilic AB block-copolymers has been shown to selfassemble into polymersomes (i.e. polymer vesicles) over the last two decades..$^{-6}$ These vesicles can be highly responsive to a range of external triggers, ${ }^{1,}{ }^{-10}$ but are limited to symmetric membranes. Introducing a third block into the selfassembling block-copolymer considerably increases the complexity of the system, hence the possible membrane

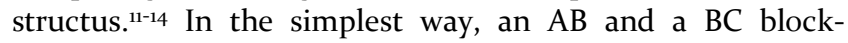
copolymer are mixed, where $A$ and $C$ are hydrophilic. These

\begin{abstract}
Nanoscopic artificial vesicles containing frotional protein transporters are fundamental for synthetic a basis for simple nanoreactors. We report on the first insertion of a functional transmembrane protein into The polymer with the composition poly(ethylene glycol)poly(diisopropylaminoethyl methacrylate)-poly(styrene sulfonate) (PEG-PDPA-PSS) was synthesized by sequential controlled radical polymerization. PEG and PSS are two
distinctively different hydrophilic blocks, allowing for a specific orientation of our protein, the light-activated proton pump Proteorhodopsin (PR), into the final
proteopolymersome. A very interesting aspect of the PEGPDPA-PSS triblock copolymers is that it allowed for simultaneous vesicle formation and oriented insertion of PR simply by adjusting the $\mathrm{pH}$. The intrinsic positive charge of aligns readily with the negative charges of the PSS on the outside of the polymersomes. The directed insertion of PR was confirmed by a light-dependent $\mathrm{pH}$ change of the proteopolymersome solution, indicating the intended
orientation. We have hereby demonstrated the first successful oriented insertion of a proton pump into an artificial asymmetric membrane.
\end{abstract}

systems are well known to form vesicles with domains on their surface if $A$ and $C$ are immiscible. ${ }^{15}$-19 When a linear $A B C$ block-copolymer is used, the formation of domains can be prevented and the polymers separate themselves to the inner and outer surface of the membrane. For steric reasons, the longer hydrophilic block prefers the outside of the membrane, while the shorter one is forced to the inner side. Such vesicles then possess a distinctively different inner and outer surface and are usually called asymmetric polymersomes..$^{12,20-22}$ These vesicles are of special interest for synthetic biology since they allow for a preferred orientation of a directional membrane transport protein (e.g. ion channels or pumps). Preferential interactions between the asymmetric membrane of the vesicle, and the intra- and extracellular domains of the integral protein enable a guided insertion (Figure 1). If the integral protein is used to create a concentration gradient over the vesicle membrane, a preferred orientation is paramount to avoid a functional short-circuit, where the substrate is transported in and out simultaneously. ${ }^{23}$

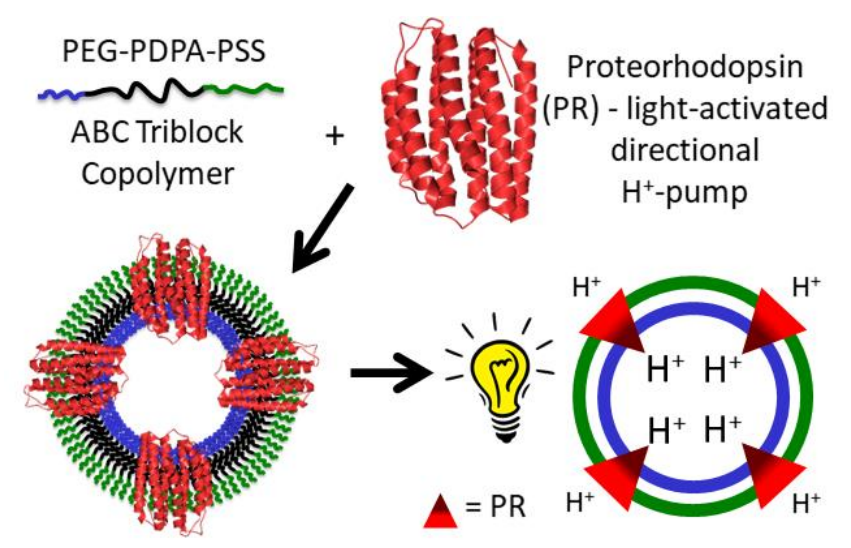

Figure 1: An $A B C$ triblock copolymer is self-assembled together with PR (shown in red). The final asymmetric polymersome then contains PR with a preferred orientation in the vesicle membrane. A simplified model shows the proton transport across the membrane from the outside to the inside of the vesicles upon illumination. The gradient equilibrates after illumination stops.

A predominant orientation of the membrane transporter would allow for establishing gradients of specific molecules or 
ions across the membrane. Such gradients are commonly used in biological processes, like the transport of nutrients or synaptic signals. ${ }^{24-25}$ Synaptic processes, for example, rely on a gradient of sodium and potassium ions to propagate electrical signals along the axons of neuronal cells. ${ }^{25}$ One of the most prominent biological processes, photosynthesis, relies on a proton gradient created across the membrane to convert light energy into chemical energy and eventually biomass. ${ }^{26}$ Recreating such a gradient in an artificial asymmetric polymeric system would mark a significant milestone in polymersomes and their role in synthetic biology. Exploiting membrane asymmetry to guide protein insertion rather than engineering the proteins allows the use of their native form. It keeps synthetic steps to a minimum and potential further applications as broad as possible. These would include the use of microbial rhodopsins to pump selected ions that could be exploited by co-reconstituted secondary active transporters. ${ }^{27}$ Possible applications would be even broader if more polymers other than poly(dimethylsiloxane) (PDMS) could be used for proteopolymersomes. However, membrane protein reconstitution is a tedious process that requires highly optimised procedures for each system. ${ }^{28-29}$ A simpler reconstitution mechanism other than integrating the protein after vesicle formation is required to overcome this shortcoming and is addressed in work presented.

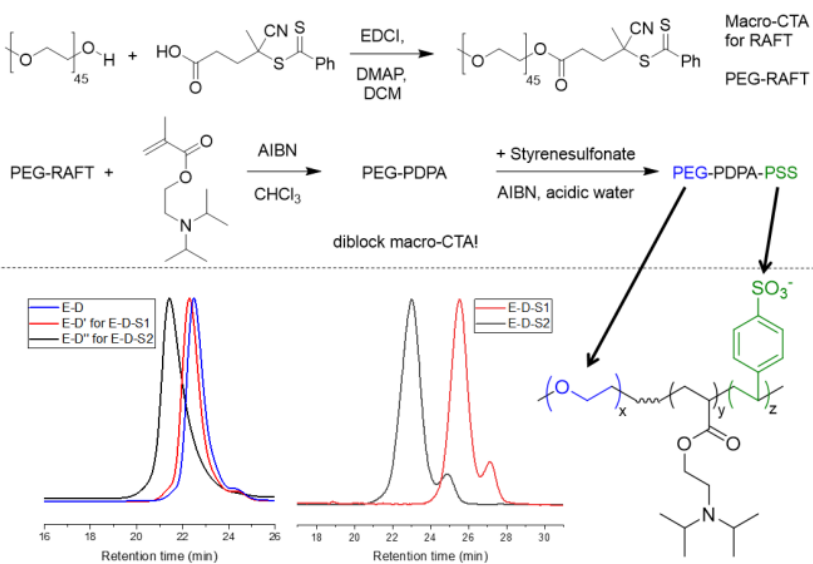

Figure 2: Steglich-esterification transforms PEG-OH into a PEG-RAFT macro-CTA, which is then used to make PEGPDPA (E-D). Using acidic aqueous conditions, PEG-PDPA is then extended with PSS to E-D-S. The final block-copolymer has the shown chemical structure. GPC traces show the distributions of the diblock (E-D polymers, in THF) and the triblock copolymers (in HFIP) E-D-S1 and E-D-S2, which contain some remaining diblock co-copolymer.

The heptahelical transmembrane protein proteorhodopsin (PR, Figure 1) is an ideal candidate to be used as a model system in such an asymmetric polymersome. ${ }^{28,30-33}$ The proton pumping activity of $\mathrm{PR}$ is light-dependent, allowing for controlled activation, and is easily detectable in vesicles by simply measuring the extravesicular $\mathrm{pH}$ upon illumination. ${ }^{3 \mathrm{O}}$, 34 Since protons can be transported easily via various means over time, the $\mathrm{pH}$ gradient can equilibrate in the dark. Most importantly, the protein has a distinct polarity,35 which potentially allows to predict its orientation after insertion into the asymmetric polymersome membrane. The intracellular side of PR has a slight positive charge whereas its extracellular side is slightly negative (Figure S 8). This polarity was further increased by engineering a decahistidine tag (His-tag) at its intracellular C-terminus. $3^{30} \mathrm{PR}$ could thus specifically align with a negatively charged polymer. Since the majority of proteins can be engineered to contain a His-tag, the results from PR have the high potential to be transferred to other membrane proteins. A comparable principle was applied on symmetric charged liposomes and led to a directed insertion of PR (up to 90\% preferred orientation). 36 We used asymmetric polymersomes made of a poly(ethylene glycol)poly(diisopropylaminoethyl methacrylate)-poly(styrene sulfonate) (PEG-PDPA-PSS) ABC triblock-copolymer to guide the directed insertion of PR. The negatively charged PSS can align PR within the asymmetric membrane, creating the desired light-dependent proton gradient (Figure 1).

$\mathrm{ABC}$ triblock copolymers exist, but are rare in comparison to $\mathrm{AB}$ diblock copolymers, since the synthetic demands are increased considerably if a third block is to be added. ${ }^{12}$ Special attention towards the synthetic procedure is thus crucial for this kind of polymers. PEG-PDPA is already a well-known polymer and was previously reported to be accessible using atom transfer radical polymerization (ATRP) and reversibleaddition fragmentation transfer radical polymerization (RAFT).37-39 The same is true for PSS, usually present as a sodium salt. This salt is soluble in water and water/methanol (up to 50/50 vol-\% ratio), but any less polar solvents do not solubilize the polymer. PEG is soluble in any of these solvents, but PDPA is only soluble in less polar solvents. However, being $\mathrm{pH}$-sensitive, the polymer becomes water-soluble if protonated, making a PEG-PDPA diblock copolymer also soluble in acidic water (as PEG-PDPA ${ }^{+}$). In contrast to classic ATRP, RAFT is feasible under these conditions. Due to the mechanism of a RAFT polymerization, impurities of homopolymers cannot be avoided, but are kept to a minimum with proper purification. We prepared a chain transfer agent (CTA) for RAFT from MeO-PEG-OH using the Steglichesterification (PEG-RAFT macro-CTA, Figure $\mathrm{S}$ 1) (Figure 2). $4^{\circ}$ The macro-CTA was then used for a polymerization of PDPA in chloroform, yielding PEG-PDPA with a low dispersity (1.181.30) after purification. We prepared a control diblock copolymer $\mathrm{PEG}_{45}-\mathrm{PDPA}_{48}\left(\mathrm{E}-\mathrm{D}\right.$, Figure $\mathrm{S}_{2}$ ) and $\mathrm{PEG}_{45}-\mathrm{PDPA}_{59}$ (E-D') and $\mathrm{PEG}_{45}-\mathrm{PDPA}_{85}$ (E-D”) precursors for the subsequent triblock copolymers (GPC traces in Figure 2). The diblock copolymers were designed to support different lengths of the following PSS chain. A longer PSS part is preferred for a directional reconstitution as a long PSS chain would avoid the inner surface of the vesicle for sterical reasons (see introduction). In order to maintain the hydrophilic-tohydrophobic balance, a longer PSS chain also meant using a longer PDPA chain to avoid the formation of micelles. Performing an aqueous RAFT polymerisation on the prepolymer with styrene sulfonate yielded the final PEGPDPA-PSS. The procedure yielded $\mathrm{PEG}_{45}-\mathrm{PDPA}_{59}-\mathrm{PSS}_{12}$ (E-D$\mathrm{S} 1,17 \mathrm{~kg} / \mathrm{mol}$, Figures 2 and $\mathrm{S} 7$ ) and $\mathrm{PEG}_{45}-\mathrm{PDPA}_{85}-\mathrm{PSS}_{22}$ (E$\mathrm{D}-\mathrm{S}_{2}, \mathbf{2 4 . 5} \mathrm{kg} / \mathrm{mol}$ Figures 2 and $\mathrm{S}_{7}$ ). GPC of the triblocks had to be conducted on a different solvent/column system for solubility reasons, but the final traces (Figure 2) showed the formation of the triblock copolymers with small impurities of the starting diblock. The latter were expected and are unlikely to impact the polarity of the self-assemblies as they are not charged. Both triblock copolymers were designed to have a block-length ratio between the hydrophilic and hydrophobic parts that favors the formation of nanoscopic polymer vesicles. ${ }^{41-42}$ We also prepared a $\operatorname{PDPA}_{50}-\mathrm{PSS}_{10}\left(\mathrm{D}-\mathrm{S}\right.$, Figure $\left.\mathrm{S}_{5}\right)$ 
block-copolymer for comparison (see section $2 \mathrm{c}$ and $2 \mathrm{~d}$ of the SI for details).

Self-assembly of the block-copolymers was performed in 10 $\mathrm{mM}$ phosphate buffered saline (PBS) at a concentration of 1 $\mathrm{mg} / \mathrm{ml}$ of polymer. Due to the protonation of PDPA after the synthesis, the polymer is completely soluble under these conditions. Adding o.1 mM NaOH solution to adjust the $\mathrm{pH}$ to 7.5 induced self-assembly of the polymer as proven by transmission electron microcopy (TEM) and dynamic light scattering (DLS) (for E-D-S2 in figures $3 a / 3 b$, for E-D-S1 in the SI (Figure $S$ 10)). The measurements indicated the expected formation of nanoscopic vesicles with an average diameter of about $200 \mathrm{~nm}$, a typical size-range for polymersomes. ${ }^{2,}$ 43-44. Cryo-TEM revealed an aqueous interior and the presence of a unilamellar membrane, proving the existence of polymersomes (Figure $3 \mathrm{c}$ ). It also gave an average membrane thickness of $13.9 \mathrm{~nm}$ ( $5 \%$ error, more details in section $4 \mathrm{~b}$ of the SI). E-D is already reported to form vesicles ${ }^{1,18,45-46}$, which was confirmed by our DLS data (see Figure S 11). Zeta potential measurements then clarified the arrangement of the triblocks in the vesicle membrane (Figure 3d). While nanoparticles of E-D (PEG is the only hydrophilic component) have a zeta potential of $-4.6 \mathrm{~V}$ and a mobility of $-0.31 \mathrm{~cm}^{2} \mathrm{~V}^{-1} \mathrm{~s}^{-1}$, both values became significantly more negative with the addition of PSS in the triblock copolymers. The zeta potentials decreased to 59.7 $\mathrm{V}$ and $-47.9 \mathrm{~V}$, and mobility values to $-4.7 \mathrm{~cm}^{2} \mathrm{~V}^{-1} \mathrm{~s}^{-1}$ and $3.8 \mathrm{~cm}^{2} \mathrm{~V}^{-1} \mathrm{~s}^{-1}$ for E-D-S1 and 2, respectively (Figure $3 \mathrm{~d}$ ). These results are strong indicators that PSS is present on the outside. Pure D-S block-copolymer gave $-46.0 \mathrm{~V}$ as zeta potential and $-3.6 \mathrm{~cm}^{2} \mathrm{~V}^{-1} \mathrm{~s}^{-1}$ as mobility, underlining the assumption that PSS is by far the main component present on the outside of the vesicle. This constitutes the prerequisite for $P R$ to be integrated into the membrane with a preferred orientation. It should also be noted that for E-D-S2 the shorter block (PEG), is on the inside of the membrane and the longer charged PSS block is on the outside of the vesicle, agreeing with previous reports. 12, 21, 47 For E-D-S1, however, PSS is the shorter block, but still remains on the outside due to repulsion of the negatively charged sulfonate groups. The repulsion is sterically hindered on the concave inside of the vesicle.
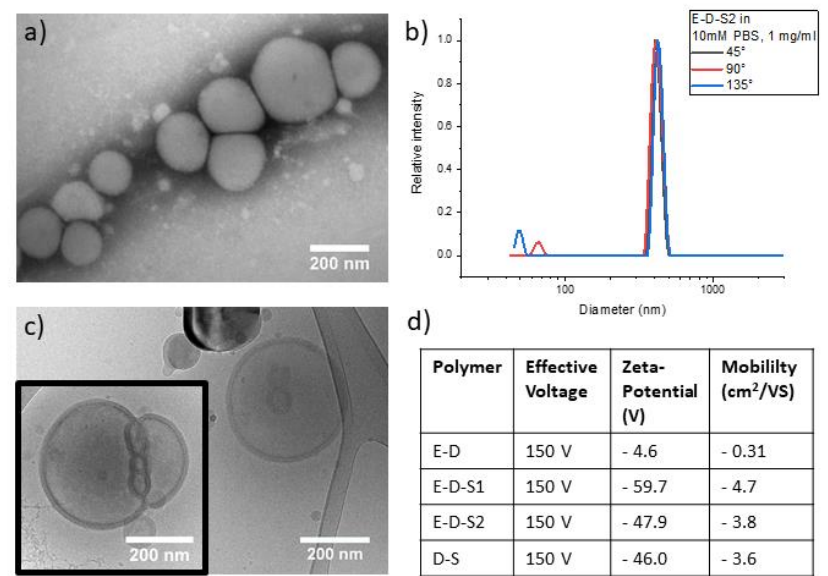

Figure 3: a) Negative stain TEM image of the self-assemblies from E-D-S2, b) including the corresponding DLS traces and c) the cryo-TEM image. Zeta potential measurements revealed a negatively charged surface of the D-S, E-D-S1 and E-D-S2 polymersomes (d).
After verification and characterization of the vesicles, reconstituting PR into the membrane was the next step. All experiments with the protein were performed in $10 \mathrm{mM}$ PBS. Protein insertion was done adapting a procedure from Messager et al, who inserted DNA nanopores into $\mathrm{pH}$ sensitive polymersomes. $4^{8}$ This in-situ approach notes a major difference to the common reconstitution after membrane formation and allows for the application of less fluid polymers. ${ }^{8}, 49^{-50}$ We were thus able to introduce the new and much simpler reconstitution mechanism required in the field. Dissolving the polymer in protein buffer $(20 \mathrm{mM}$ potassium phosphate $\mathrm{pH} 7 \cdot 5,150 \mathrm{mM} \mathrm{NaCl}$, see section za of the SI) and then adding the purified protein ensured solubility of both components. Diluting the protein buffer with a weak base ten times made the protein solution instable and resulted in a $\mathrm{pH}$ increase to $7 \cdot 5$. The change in $\mathrm{pH}$ induced the self-assembly of the triblock-copolymer by making PDPA hydrophobic. As a result, the hydrophobic parts of $P R$ aligned with the membrane-forming polymer during the formation of the proteopolymersomes. Centrifugation and resuspension in buffer yielded purified vesicles with a protein-polymer ratio of about 1:400 (see section 4c of the SI for details). Proteopolymersomes using symmetric membranes used a protein-to polymer ratio of 1:10o. Interestingly for proteoliposomes, PR:lipid ratios of 1:100 up to 1:1000 were reported. ${ }^{28,} 34$ Using a rough estimation of the amount of polymer chains per vesicle, this yields about 100-135 PR per vesicle (see section $4 \mathrm{~d}$ of the SI). PR has only one solvent accessible thiol unit, i.e. cysteine residue $\mathrm{C}_{175}$, located on the intracellular side (see Figure S 9). Thus, the amount of directed inserted protein can be estimated by determining the amount of accessible thiol groups in comparison to the whole amount of protein present. An assay using Ellmann's reagent ${ }^{51-}$ ${ }^{52}$ revealed the orientation of the protein in the polymersome membrane. Normalizing these values to the total protein content gave the percentages of the intracellular side of PR on the outside of the polymersome. Vesicles made from E-D-S2 yielded $85 \%$ with this orientation compared to $70 \%$ with E-D$\mathrm{S} 1$ vesicles. The same assay resulted in $35 \%$ for the vesicles from AB block copolymer (Table $S_{1}$ ). Since faulty insertions cannot be avoided, the value for vesicles $A B$ diblock copolymer represents an approximation to a statistical insertion. Furthermore, the assay allows to quantify the amount of PR found in the vesicles, which correlates exactly to amount of protein added beforehand (see section $4 \mathrm{~d}$ of the SI for details). This correlation strongly underlines the numbers of directed insertion just discussed. Altoghether, the assay proved that the triblock copolymer, especially E-D-S2 leads to a directional insertion of PR. Therefore, both triblockcopolymers should lead to a proton transport into the proteopolymersomes.

PR pumps protons from the intracellular side towards the extracellular side (Figure 4a).27, 30, 34 Our PR is reversely oriented as the native intracellular side is aligned with the PSS on the outside of the vesicles. Protons will thus be pumped into the proteopolymersomes due to the inside-out oriented PR (Figure 4b), possibly protonating some tertiary amines of PDPA. Measuring the $\mathrm{pH}$ change of the extravesicular solution upon illuminating E-D-S2 proteopolymersomes confirmed the functional protein insertion. Light absorption by the PR containing polymersomes induced proton pumping into the vesicles. This resulted in a rising extravesicular $\mathrm{pH}$, which receded after putting the solution back into the dark. 
Irrespective of the polymer, a maximal amplitude of 0,08 units was reached. Proteoliposomes with PR reached twice the amplitude, $3^{30}, 34$ but used longer cycles, indicating that our proteopolymersomes operate at a similar range than liposomes. Repeating the pumping cycle was possible multiple times (see cycles shown in Figure 4c). Osmosis during the dark periods lead to an equilibration of the $\mathrm{pH}$ gradient. This exponential nature of the decay means that it becomes slower over time, explaining why no initial $\mathrm{pH}$ value was reached. Proteopolymersomes of the second triblock copolymer, E-DS1, also exhibited pumping activity, although less prominent (see Figure $\mathrm{S}$ 12). Controls with no PR gave no $\mathrm{pH}$ response (Figure $\mathrm{S}_{13}$ ). The proton pumping measurements support that the protein has been inserted with a preferred orientation and retained its functionality in the polymeric membrane. a)

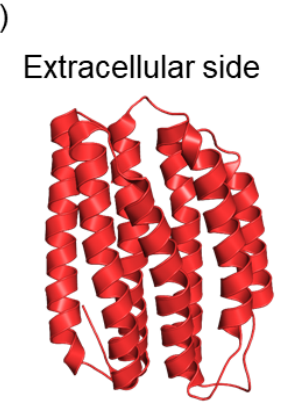

Intracellular side - slight positive charge -
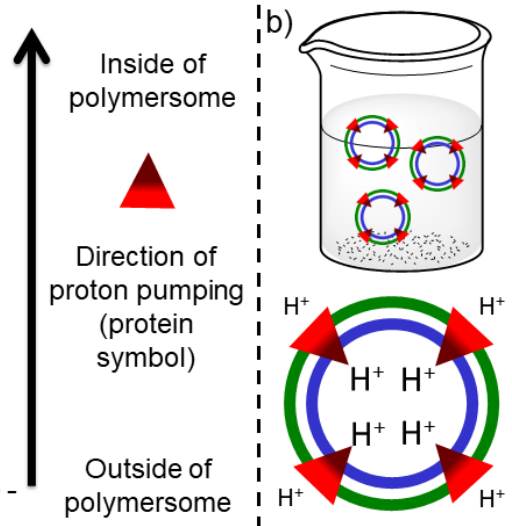

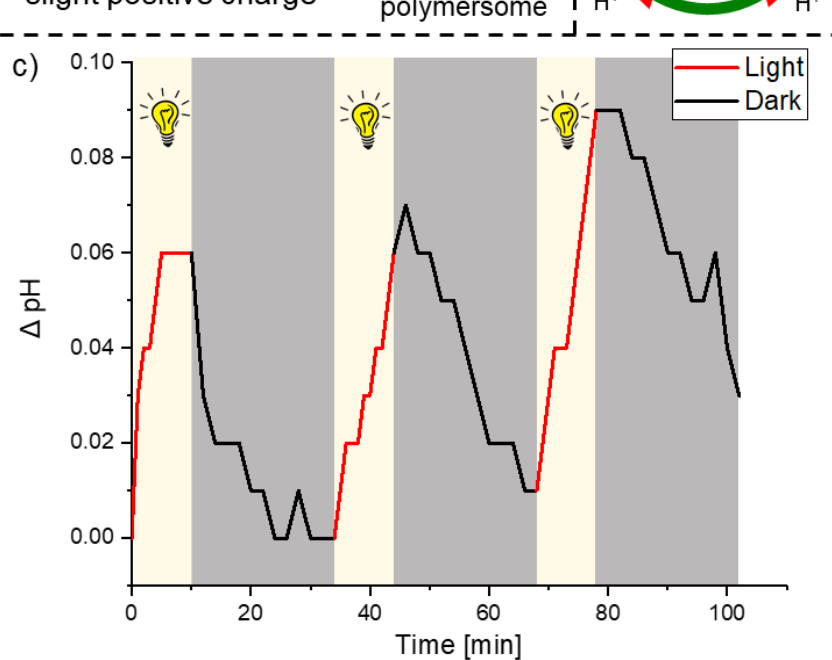

Figure 4: a) PR pumps protons from its intracellular to its extracellular side. b) Alignment of PR with the asymmetric polymersome membrane leads to directional insertion (0.75 mg polymer and $3 \mu \mathrm{g}$ PR in o.1 mL protein buffer and o.9 $\mathrm{mL}$ of 10 $\mathrm{mM}$ PBS) and results in a light-dependent proton gradient (higher concentration inside). c) Proton pumping activity of PR-functionalized polymersomes from E-D-S2 over three illumination (10 minutes) and darkness cycles (24 minutes) using $1 \mathrm{ml}$ of the sample ( $0.75 \mathrm{mg} / \mathrm{ml}$ polymer).

Sequential RAFT polymerization led to a narrowly dispersed amphiphilic ABC triblock copolymer (PEG-PDPA-PSS), which self-assembled into the desired asymmetric polymersomes. Due to the negatively charged PSS, the inserted PR aligned its positively charged end with the PSS, promoting a directional protein insertion. The insertion exploiting a $\mathrm{pH}$ switch marks a significant improvement for proteopolymersomes as it is a much simpler reconstitution mechanism that is not available for proteoliposomes. Pumps like PR require a defined orientation to enable an oriented exchange of solutes. Since all pumps can be equipped with a positive charge at the desired terminus, e.g. by an engineered His-tag, our research is transferable to other directional pumps like bacteriorhodopsin and microbial rhodopsins in general. Due to applying a $\mathrm{pH}$ sensitive hydrophobic block, this is the first asymmetric nanoreactor which is built completely during selfassembly. Here we have demonstrated that polymersomes with an asymmetric membrane are suitable to achieve a directional and functional insertion of a vectorial membrane transport protein such as PR. We are confident that these results will mark an important milestones in the field of synthetic biology, especially concerning the engineering of energy-dependent protein nanoreactors.

\section{ASSOCIATED CONTENT}

\section{Supporting Information}

The Supporting Information is available free of charge on the ACS Publications website. Details on the synthetic procedures, analytical data on the polymers, details on protein purification, experimental procedures on protein insertion and analysis of the vesicle/protein combination can be found in the supporting information brief description (PDF).

\section{AUTHOR INFORMATION}

\section{Corresponding Author}

E-Mail addresses: Wolfgang.Meier@unibas.ch (W.M.), Dimitrios.Fotiadis@ibmm.unibe.ch (D.F.)

\section{Notes}

The authors declare no competing financial interests. All authors contributed to the present manuscript.

\section{ACKNOWLEDGMENT}

We would like to acknowledge Carola Alampi from c-cina (Uni Basel) for the cryo-TEM. All authors would like to thank the Swiss National Science Foundation (SNSF) for funding, especially in light of the National Centre of Competence in Research Molecular Systems Engineering (NCCR-MSE).

\section{REFERENCES}

1. Gaitzsch, J.; Huang, X.; Voit, B., Engineering Functional Polymer Capsules toward Smart Nanoreactors, Chem. Rev. 2016, 116 (3), 10531093.

2. Najer, A.; Wu, D. L.; Vasquez, D.; Palivan, C. G.; Meier, W., Polymer nanocompartments in broad-spectrum medical applications, Nanomedicine 2013, 8 (3), 425-447.

3. Rhim, T.; Lee, K. Y., Exosome and Polymersome for Potential Theranostic Applications, Macromol. Res. 2016, 24 (7), 577-586.

4. Pachioni-Vasconcelos, J. D.; Lopes, A. M.; Apolinario, A. C.; Valenzuela-Oses, J. K.; Costa, J. S. R.; Nascimento, L. D.; Pessoa, A.; Barbosa, L. R. S.; Rangel-Yagui, C. D., Nanostructures for protein drug delivery, Biomater. Sci. 2016, 4 (2), 205-218.

5. Messager, L.; Gaitzsch, J.; Chierico, L.; Battaglia, G., Novel aspects of encapsulation and delivery using polymersomes, Curr. Opin. Pharmacol. 2014, 18, 104-111.

6. Kim, K. T.; Meeuwissen, S. A.; Nolte, R. J. M.; van Hest, J. C. M., Smart nanocontainers and nanoreactors, Nanoscale 2010, 2 (6), 844858. 
7. Gaitzsch, J.; Appelhans, D.; Voit, B., Responsive Polymersomes, Nachr. Chem. 2012, 60 (12), 1176-1180.

8. Palivan, C. G.; Goers, R.; Najer, A.; Zhang, X.; Car, A.; Meier, W., Bioinspired polymer vesicles and membranes for biological and medical applications, Chem. Soc. Rev. 2016, 45 (2), 377-411.

9. Gaitzsch, J.; Welsch, P. C.; Folini, J.; Schoenenberger, C.-A.; Anderson, J. C.; Meier, W. P., Revisiting Monomer Synthesis and Radical Ring Opening Polymerization of Dimethylated MDO Towards Biodegradable Nanoparticles for Enzymes, Eur. Polym. J. 2018, 101, 113-119.

10. Le Meins, J. F.; Sandre, O.; Lecommandoux, S., Recent trends in the tuning of polymersomes' membrane properties, Eur. Phys. J. E Soft Matter 2011, 34 (2), 1-17.

11. Groschel, A. H.; Muller, A. H. E., Self-assembly concepts for multicompartment nanostructures, Nanoscale 2015, 7 (28), 11841-11876.

12. Konishcheva, E.; Daubian, D.; Gaitzsch, J.; Meier, W., Synthesis of Linear ABC Triblock Copolymers and Their Self-Assembly in Solution, Helv. Chim. Acta 2018, 101 (2), e1700287.

13. Coumes, F.; Beaute, L.; Domurado, D.; Li, S.; Lecommandoux, S.; Coudane, J.; Darcos, V., Self-assembly of well-defined triblock copolymers based on poly(lactic acid) and poly(oligo(ethylene glycol) methyl ether methacrylate) prepared by ATRP, RSC Advances 2016, 6 (58), 53370-53377.

14. Meeuwissen, S. A.; Bruekers, S. M. C.; Chen, Y. C.; Pochan, D. J.; van Hest, J. C. M., Spontaneous shape changes in polymersomes via polymer/polymer segregation, Polym. Chem. 2014, 5 (2), 489-501.

15. Du, J.; Armes, S. P., Patchy multi-compartment micelles are formed by direct dissolution of an $\mathrm{ABC}$ triblock copolymer in water, Soft Matter 2010, 6 (19), 4851-4857.

16. LoPresti, C.; Massignani, M.; Fernyhough, C.; Blanazs, A.; Ryan, A. J.; Madsen, J.; Warren, N. J.; Armes, S. P.; Lewis, A. L.; Chirasatitsin, S.; Engler, A. J.; Battaglia, G., Controlling Polymersome Surface Topology at the Nanoscale by Membrane Confined Polymer/Polymer Phase Separation, ACS Nano 2011, 5 (3), 1775-1784.

17. Ruiz-Perez, L.; Madsen, J.; Themistou, E.; Gaitzsch, J.; Messager, L.; Armes, S. P.; Battaglia, G., Nanoscale detection of metal-labeled copolymers in patchy polymersomes, Polym. Chem. 2015, 6 (11), 20652068.

18. Ruiz-Perez, L.; Messager, L.; Gaitzsch, J.; Joseph, A.; Sutto, L.; Gervasio, F. L.; Battaglia, G., Molecular engineering of polymersome surface topology, Science Advances 2016, 2 (4), e1500948.

19. Gaitzsch, J.; Chudasama, V.; Morecroft, E.; Messager, L.; Battaglia, G., Synthesis of an Amphiphilic Miktoarm Star Terpolymer for Self-Assembly into Patchy Polymersomes, ACS Macro Lett. 2016, 5 (3), 351-354.

20. Stoenescu, R.; Graff, A.; Meier, W., Asymmetric ABC-triblock copolymer membranes induce a directed insertion of membrane proteins, Macromol. Biosci. 2004, 4 (10), 930-935.

21. Konishcheva, E. V.; Zhumaev, U. E.; Meier, W. P., PEO-b-PCLb-PMOXA Triblock Copolymers: From Synthesis to Microscale Polymersomes with Asymmetric Membrane, Macromolecules 2017, 50 (4), 1512-1520.

22. Peyret, A.; Zhao, H.; Lecommandoux, S., Preparation and Properties of Asymmetric Synthetic Membranes Based on Lipid and Polymer Self-Assembly, Langmuir 2018, 34 (11), 3376-3385.

23. Hirschi, S.; Stauffer, M.; Harder, D.; Müller, D. J.; Meier, W.; Fotiadis, D., Engineering and Assembly of Protein Modules into Functional Molecular Systems, Chimia 2016, 70 (6), 398-401.

24. Shi, Y., Common Folds and Transport Mechanisms of Secondary Active Transporters, Annu. Rev. Biophys. 2013, 42 (1), 51-72.

25. Bean, B. P., The action potential in mammalian central neurons, Nat. Rev. Neurosci. 2007, 8, 451.

26. Nelson, N.; Ben-Shem, A., The complex architecture of oxygenic photosynthesis, Nat. Rev. Mol. Cell Biol. 2004, 5, 971.

27. Claassens, N. J.; Volpers, M.; dos Santos, V.; van der Oost, J.; de Vos, W. M., Potential of proton-pumping rhodopsins: engineering photosystems into microorganisms, Trends Biotechnol. 2013, 31 (11), 633-642.

28. Goers, R.; Thoma, J.; Ritzmann, N.; Di Silvestro, A.; Alter, C.; Gunkel-Grabole, G.; Fotiadis, D.; Müller, D. J.; Meier, W., Optimized reconstitution of membrane proteins into synthetic membranes, Communications Chemistry 2018, 1 (1), 35 .
29. Itel, F.; Najer, A.; Palivan, C. G.; Meier, W., Dynamics of Membrane Proteins within Synthetic Polymer Membranes with Large Hydrophobic Mismatch, Nano Lett. 2015, 15 (6), 3871-3878.

30. Harder, D.; Hirschi, S.; Ucurum, Z.; Goers, R.; Meier, W.; Muller, D. J.; Fotiadis, D., Engineering a Chemical Switch into the Lightdriven Proton Pump Proteorhodopsin by Cysteine Mutagenesis and Thiol Modification, Angew. Chem., Int. Ed. 2016, 55 (31), 8846-8849.

31. Jahnke, J. P.; Idso, M. N.; Hussain, S.; Junk, M. J. N.; Fisher, J. M.; Phan, D. D.; Han, S.; Chmelka, B. F., Functionally Active Membrane Proteins Incorporated in Mesostructured Silica Films, J. Am. Chem. Soc. 2018, 140 (11), 3892-3906.

32. Han, C. T.; Hussain, S.; Idso, M. N.; Narayanan, S.; Chan, T.; Han, S., Role of the Lipid Membrane on the Oligomeric Assembly and Function of Proteorhodopsin, Biophys. J. 2018, 114 (3), 61A-62A.

33. Reckel, S.; Gottstein, D.; Stehle, J.; Löhr, F.; Verhoefen, M.-K.; Takeda, M.; Silvers, R.; Kainosho, M.; Glaubitz, C.; Wachtveitl, J.; Bernhard, F.; Schwalbe, H.; Güntert, P.; Dötsch, V., Solution NMR Structure of Proteorhodopsin, Angew. Chem., Int. Ed. 2011, 50 (50), $11942-11946$.

34. Ritzmann, N.; Thoma, J.; Hirschi, S.; Kalbermatter, D.; Fotiadis, D.; Müller, D. J., Fusion Domains Guide the Oriented Insertion of Light-Driven Proton Pumps into Liposomes, Biophys. J. 2017, 113 (6), 1181-1186.

35. Liang, H.; Whited, G.; Nguyen, C.; Stucky, G. D., The directed cooperative assembly of proteorhodopsin into $2 \mathrm{D}$ and ${ }_{3} \mathrm{D}$ polarized arrays, Proc. Natl. Acad. Sci. 2007, 104 (20), 8212-8217.

36. Tunuguntla, R.; Bangar, M.; Kim, K.; Stroeve, P.; Ajo-Franklin, Caroline M.; Noy, A., Lipid Bilayer Composition Can Influence the Orientation of Proteorhodopsin in Artificial Membranes, Biophys. J. 2013, 105 (6), 1388-1396.

37. Siegwart, D. J.; Oh, J. K.; Matyjaszewski, K., ATRP in the design of functional materials for biomedical applications, Prog. Polym. Sci. 2012, 37 (1), 18-37.

38. Braunecker, W. A.; Matyjaszewski, K., Controlled/living radical polymerization: Features, developments, and perspectives, Prog. Polym. Sci. 2007, 32 (1), 93-146.

39. Moad, G.; Rizzardo, E.; Thang, S. H., Living Radical Polymerization by the RAFT Process - A Second Update, Aust. J. Chem. 2009, 62 (11), 1402-1472.

40. Rifaie-Graham, O.; Ulrich, S.; Galensowske, N. F. B.; Balog, S.; Chami, M.; Rentsch, D.; Hemmer, J. R.; Read de Alaniz, J.; Boesel, L. F.; Bruns, N., Wavelength-Selective Light-Responsive DASAFunctionalized Polymersome Nanoreactors, J. Am. Chem. Soc. 2018, 140 (25), 8027-8036.

41. Fetsch, C.; Gaitzsch, J.; Messager, L.; Battaglia, G.; Luxenhofer, R., Self-Assembly of Amphiphilic Block Copolypeptoids - Micelles, Worms and Polymersomes, Sci. Rep. 2016, 6.

42. Blanazs, A.; Armes, S. P.; Ryan, A. J., Self-Assembled Block Copolymer Aggregates: From Micelles to Vesicles and their Biological Applications, Macromol. Rapid Commun. 2009, 30 (4-5), 267-277.

43. Onaca, O.; Enea, R.; Hughes, D. W.; Meier, W., Stimuli-Responsive Polymersomes as Nanocarriers for Drug and Gene Delivery, Macromol. Biosci. 2009, 9 (2), 129-139.

44. Brinkhuis, R. P.; Rutjes, F. P. J. T.; van Hest, J. C. M., Polymeric vesicles in biomedical applications, Polym. Chem. 2o11, 2 (7), 14491462.

45. Wong, A. S. M.; Czuba, E.; Chen, M. Z.; Yuen, D.; Cupic, K. I.; Yang, S. L.; Hodgetts, R. Y.; Selby, L. I.; Johnston, A. P. R.; Such, G. K., pH-Responsive Transferrin-pHlexi Particles Capable of Targeting Cells in Vitro, ACS Macro Lett. 2017, 6 (3), 315-320.

46. Massignani, M.; LoPresti, C.; Blanazs, A.; Madsen, J.; Armes, S. P.; Lewis, A. L.; Battaglia, G., Controlling Cellular Uptake by Surface Chemistry, Size, and Surface Topology at the Nanoscale, Small 2oog, 5 (21), 2424-2432.

47. Stoenescu, R.; Meier, W., Vesicles with asymmetric membranes from amphiphilic ABC triblock copolymers, Chem. Commun. 20o2, (24), 3016-3017.

48. Messager, L.; Burns, J. R.; Kim, J.; Cecchin, D.; Hindley, J.; Pyne, A. L. B.; Gaitzsch, J.; Battaglia, G.; Howorka, S., Biomimetic Hybrid Nanocontainers with Selective Permeability, Angew. Chem., Int. Ed. 2016, 55 (37), 11106-11109. 
49. Lomora, M.; Gunkel-Grabole, G.; Mantri, S.; Palivan, C. G., Biocatalytic nanocompartments for in situ production of glucose-6-phosphate, Chem Commun (Camb) 2017, 53 (73), 10148-10151.

5o. Edlinger, C.; Einfalt, T.; Spulber, M.; Car, A.; Meier, W.; Palivan, C. G., Biomimetic Strategy To Reversibly Trigger Functionality of Catalytic Nanocompartments by the Insertion of $\mathrm{pH}$-Responsive Biovalves, Nano Lett. 2017, 17 (9), 5790-5798.
51. Lysaa, R. A.; Warren, D. J.; Sylte, I.; Aarbakke, J., Effect of the glutathione/glutathione disulfide redox couple on thiopurine methyltransferase, Biochem. Pharmacol. 20o1, 61 (6), 707-714.

52. Ellman, G. L., Tissue Sulfhydryl Groups, Arch. Biochem. Biophys. 1959, $82(1), 70-77$. 
1

2

3

4

5

6

7

8

9

10

11

12

13

14

15

16

17

18

19

20

21

22

23

24

25

26

27

28

29

30

31

32

33

34

35

36

37

38

39

40

41

42

43

44

45

46

47

48

49

50

51

52

53

54

55

56

57

58

59

60

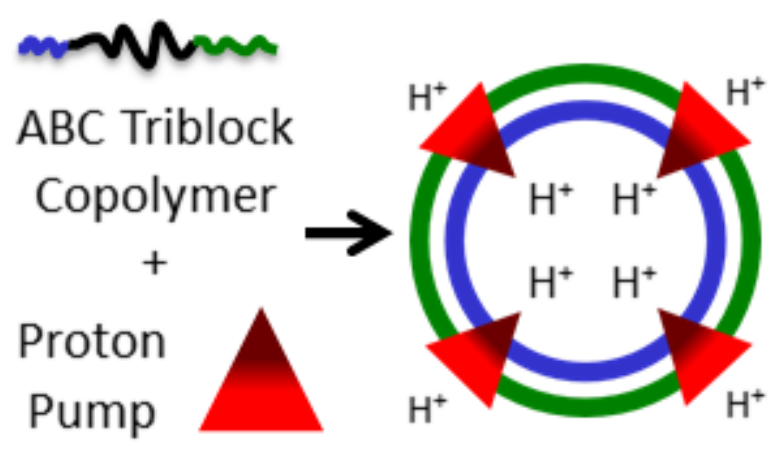

TOC Artwork 